\title{
Tratamento químico de sementes sobre o desenvolvimento de mancha marrom em plantas de trigo
}

\author{
Chemical treatment in seeds on the development of the spot blotch in wheat plants
}

\author{
Mayra Suemy Ishikawa' ${ }^{I}$ Inês Cristina de Batista FonsecaII Seiji Igarashi'
}

\section{RESUMO}

\begin{abstract}
O objetivo do trabalho foi avaliar o efeito dos fungicidas difenoconazole e carboxin + thiram aplicados em sementes de trigo cultivares 'CD 104' $e$ 'OR Mirante', inoculadas com Cochliobolus sativus. $O$ delineamento experimental foi inteiramente casualizado, em esquema fatorial $2 \times 3$ ( 2 cultivares e 2 fungicidas + testemunha sem controle) em sete repetições. $O$ fungo foi isolado e reproduzido em meio de cultura BDA (batata-dextrose-ágar) e, posteriormente, multiplicado em sementes de trigo pré-cozidas, constituindo a fonte de inóculo. As avaliações foram do número de lesões na folha basal de cinco plantas por vaso aos 22, 25, 29, 31, 35 e 38 dias após a semeadura (DAS) e aos 41 dias foram avaliados o comprimento (cm), massa fresca $(\mathrm{g})$ e seca $(\mathrm{g})$ da parte aérea e das raízes. A partir das avaliações do número de lesões, também foi calculada a área abaixo da curva de progresso da doença $(A A C P D)$, cujos dados foram submetidos à análise de variância $e$ as médias comparadas pelo teste de Tukey, a $5 \%$ de probabilidade. A cultivar 'CD 104' foi mais suscetível ao patógeno do que 'OR Mirante'; difenoconazole foi eficiente no controle da doença na parte aérea, enquanto carboxin + thiram se igualou à testemunha; os dois fungicidas interferiram negativamente no desenvolvimento das plantas, uma vez que as médias de comprimento, massa fresca e seca da parte aérea e das raízes obtidas das sementes tratadas é inferior à média das sementes não tratadas.
\end{abstract}

Palavras-chave: Triticum aestivum, Bipolaris sorokiniana, difenoconazole, carboxin + thiram.

\section{ABSTRACT}

The objective of this research was to evaluate the effect of fungicides difenoconazole and carboxin + thiram applied in seed wheat cultivars 'CD 104' and 'OR Mirante', inoculated with Cochliobolus sativus. The experimental design was completely randomized in a $2 \times 3$ factorial design ( 2 cultivars and 2 fungicides + untreated control) in seven replications. The fungi was isolated and reproduced in PDA culture medium (potato-dextrose-agar) and subsequently multiplied in seeds of wheat pre-cooked and is the source of inoculum. The evaluations were the number of lesions in the basal leaf of five plants per pot at 22, 25, 29, 31, 35 and 38 days after sowing (DAS), and at 41DAS were evaluated the length $(\mathrm{cm})$, fresh weight $(\mathrm{g})$ and dry weight $(\mathrm{g})$ of shoot and root. From the evaluations of the number of lesions was also calculated the area under the disease progress curve (AUDPC). The datas were subjected to analysis of variance and means were compared by Tukey test at 5\% probability. The 'CD 104' cultivar was more susceptible to the pathogen than 'OR Mirante'; difenoconazole was efficient to control the disease as carboxin + thiram equaled the witness; both fungicides interfered negatively on plant development, since the average length, fresh weight and dry shoot and root obtained from treated seed is lower than the untreated seeds.

Key words: Triticum aestivum, Bipolaris sorokiniana, difenoconazole, carboxin + thiram.

\section{INTRODUÇÃO}

O trigo (Triticum aestivum L.) é o cereal de maior produção mundial e, no Brasil, sua produção oscila entre 5 e 6 milhões de toneladas por ano, sendo a região Sul responsável por 90\% da produção; entretanto, a cultura vem sendo introduzida paulatinamente na região do cerrado, em cultivo irrigado ou sequeiro (EMBRAPA TRIGO, 2010).

'Programa de Pós-graduação em Agronomia, Universidade Estadual de Londrina (UEL), Rodovia Celso Garcia Cid/PR 445, Km 380, Campus Universitário, 86051-990, Londrina, PR, Brasil. E-mail: maishikawa@gmail.com. Autor para correspondência.

IIDepartamento de Agronomia, Centro de Ciências Agrárias (CCA), UEL, Londrina, PR, Brasil. 
Apesar dessa importância, seu potencial não tem sido explorado devidamente, pois uma limitação de destaque é o frequente aparecimento de doenças que causam queda da produtividade (ARRUDA et al., 2005). Dados sobre danos causados por doenças na cultura do trigo são bastante variáveis, especialmente porque diversos fatores interferem no estabelecimento e desenvolvimento das epidemias, tais como as condições ambientais, a maior ou menor suscetibilidade das cultivares, a agressividade dos patógenos e a época do início da infecção (MEHTA, 1993).

A mancha marrom, cujo agente causal é Cochliobolus sativus (S. Ito \& Kurib.), Drechsler ex Dastur. (anamorfo: Bipolaris sorokiniana (Sacc). Shoemaker), é considerada uma das doenças mais importantes para a cultura do trigo na América do Sul, chegando a acarretar perdas de até $80 \%$ no rendimento (MEHTA, 1993).

Os sintomas iniciais consistem em pequenas manchas foliares ovais com cerca de três a quatro milímetros, de coloração castanho-escura a negra, que, com a evolução, ocorre aumento do seu tamanho e adquirem típica forma elíptica, além da abundante presença de conídios. As lesões têm uma margem castanho-escura com centro castanho-claro e logo se tornam necróticas, sendo que, quando coalescem, toda a folha murcha e cai prematuramente (MEHTA, 1993).

Entre as medidas de controle das doenças do trigo, o emprego de cultivares resistentes é a mais econômica e eficaz, pois, embora o melhoramento genético venha alcançando êxito nesse aspecto, até o momento não há cultivares resistentes a todas as enfermidades. Portanto, a adoção do controle químico com fungicidas é ainda uma medida necessária para estabilizar a produtividade deste cereal (GOULART \& PAIVA, 1991).

O tratamento de sementes de trigo com fungicidas é um dos métodos mais simples e de custo relativamente baixo, que, além de controlar patógenos transmitidos via semente, pode ainda oferecer proteção prolongada à entrada de patógenos na parte aérea (GOULART, 1999). Também o controle das doenças fúngicas da parte aérea via tratamento de sementes é uma alternativa com facilidade de uso e menor risco de contaminação ambiental (PICININI \& FERNANDES, 2001) e, segundo AZEVEDO (1996), quando a doença ocorre cedo, seu controle via tratamento de sementes é considerado viável.

Portanto, este estudo teve como objetivo determinar o efeito de fungicidas utilizados no tratamento químico de sementes de trigo sobre o controle de mancha marrom inoculada em plântulas de trigo.

\section{MATERIAL E MÉTODOS}

O trabalho foi realizado em casa de vegetação do Departamento de Agronomia, da Universidade Estadual de Londrina, com as cultivares 'OR Mirante' e 'CD 104', consideradas suscetíveis à mancha marrom do trigo e os fungicidas difenoconazole e carboxin + thiram, nas doses de 30 e $50+50 \mathrm{~g}$ do ingrediente ativo, respectivamente, por $100 \mathrm{~kg}$ de sementes, resultando em quatro tratamentos mais duas testemunhas não tratadas. Cada unidade experimental foi composta por um vaso contendo 15 plantas, em delineamento experimental inteiramente casualizado, em esquema fatorial 2x3 (2 cutivares e 2 fungicidas + testemunha sem controle), com sete repetições, totalizando 42 parcelas.

Os seis tratamentos foram constituídos da seguinte forma: $\mathrm{T}_{1}$ ('OR Mirante' x carboxin + thiram); $\mathrm{T}_{2}$ ('OR Mirante’ x difenoconazole); $\mathrm{T}_{3}$ ('OR Mirante' $\mathrm{x}$ sem fungicida); $\mathrm{T}_{4}$ ('CD 104' x carboxin + thiram); $\mathrm{T}_{5}$ ('CD 104' x difenoconazole) e $\mathrm{T}_{6}$ ('CD104’ x sem fungicida).

Os lotes de sementes das duas cultivares foram previamente submetidos ao blotter test, pelo método do papel de filtro a fim de constatar sua qualidade sanitária, de acordo com o Manual de análise sanitária de sementes (BRASIL, 2009).

O patógeno $\boldsymbol{C}$. sativus foi inicialmente isolado a partir de lesões típicas de folhas, colmos e sementes infectados, sendo posteriormente multiplicado em meio de cultura BDA (batata-dextroseágar). Após a multiplicação, todo o meio de cultura contendo micélios e esporos do patógeno foi misturado a sementes de trigo previamente cozidas e esterelizadas, nas quais os fungos continuaram se multiplicando a fim de constituir a fonte de inóculo, baseado em metodologia de JOSHI et al. (1969).

Os vasos foram preenchidos em camadas com $60 \%$ de solo, $20 \%$ de substrato comercial e $10 \%$ de mistura contendo solo, areia e casca de arroz carbonizada na proporção 1:1:1. O solo utilizado foi submetido à análise química de macronutrientes e previamente corrigido com fertilizante químico, incorporando-se $20 \mathrm{~kg} \mathrm{ha}^{-1}$ de $\mathrm{N}, 75 \mathrm{~kg} \mathrm{ha}^{-1}$ de $\mathrm{P}_{2} \mathrm{O}_{5}$ e $70 \mathrm{~kg} \mathrm{ha}^{-1}$ de $\mathrm{K}_{2} \mathrm{O}$, seguindo recomendação de FRONZA et al. (2008).

As sementes foram tratadas com os fungicidas em sacos plásticos, agitando-as vigorosamente até obterem cobertura uniforme do produto. Após 10 dias da semeadura, cinco gramas do inóculo da doença foram distribuídos uniformemente em cada vaso, que foram posteriormente cobertos com sacos plásticos 
transparentes durante três dias a fim de manter condições ideais para o contínuo desenvolvimento do fungo. As condições de umidade foram verificadas diariamente e, quando necessário, fez-se irrigação por aspersão até atingir a capacidade de campo.

As plantas foram avaliadas aos 22, 25, 29, 31, 35 e 38 dias após a semeadura (DAS), contando-se o número de lesões da folha basal (NL) de cinco plantas aleatórias por vaso. Ao final de seis avaliações, 41 dias após a semeadura (DAS), foram avaliados o comprimento da parte aérea (CPA), comprimento da raiz (CR), massa fresca da parte aérea (MFPA) e das raízes (MFR), massa seca da parte aérea (MSPA) e das raízes (MSR) de todas as plantas; o comprimento foi medido em centímetros e as massas em gramas.

Através dos dados de quantificação das doenças, foram determinadas as áreas abaixo da curva de progresso da doença (AACPD). Os dados foram submetidos à análise de variância e as médias comparadas pelo teste de Tukey a 5\% de probabilidade.

\section{RESULTADOS E DISCUSSÃO}

Nos resultados obtidos pelo blotter test, as sementes das cultivares 'OR Mirante' e 'CD 104' estavam, respectivamente, com zero e $1 \%$ de incidência de $\boldsymbol{C}$. sativus. Dessa forma, infere-se que as lesões de mancha marrom avaliadas eram provenientes da fonte de inóculo distribuída nos vasos e não das sementes. De acordo com os resultados obtidos para o número de lesões por folha em cada avaliação (Tabela 1), observou-se que houve interação significativa entre os fatores cultivar e fungicida somente na segunda avaliação, realizada aos 25 dias após a semeadura (DAS). A interação significativa indica que a resposta ao tratamento variou com o grau de suscetibilidade das cultivares bem como com a eficiência e persistência do fungicida utilizado da seguinte forma: a cultivar ' $\mathrm{CD}$ 104' foi mais suscetível que a 'OR Mirante', porém, quando utilizado difenoconazole, não foi possível observar essa diferença, demonstrando um efeito positivo desse fungicida nesta avaliação.

Tabela 1 - Comparação das médias do número de lesões por folha basal aos 22, 25, 29, 31, 35 e 38 dias após a semeadura, em plântulas de trigo das cultivares 'OR Mirante' e 'CD 104' inoculadas com C. sativus e submetidas ao tratamento de sementes com carboxin+thiram e difenoconazole, em comparação com a testemunha não tratada.

\begin{tabular}{|c|c|c|c|c|c|}
\hline \multirow{2}{*}{ Avaliação (DAS) } & \multirow{2}{*}{ Cultivares } & \multicolumn{4}{|c|}{ - } \\
\hline & & Carboxin + Thiram & Difenoconazole & Testemunha & Médias \\
\hline \multirow{3}{*}{22} & 'OR Mirante’ & 2,0 & 1,7 & 1,7 & $1,8 \mathrm{~A}$ \\
\hline & ‘CD 104’ & 3,5 & 1,6 & 3,4 & $2,8 \mathrm{~B}$ \\
\hline & Média & $2,8 \mathrm{~b}$ & 1,6 a & $2,6 \mathrm{ab}$ & $\mathrm{CV}=50,9 \%$ \\
\hline \multirow{3}{*}{25} & 'OR Mirante’ & $2,1 \mathrm{~A} \mathrm{a}$ & $1,3 \mathrm{~A} \mathrm{a}$ & $1,7 \mathrm{~A} \mathrm{a}$ & 1,7 \\
\hline & 'CD 104’ & 3,7 B b & $1,3 \mathrm{~A} \mathrm{a}$ & $4,2 \mathrm{~B} \mathrm{~b}$ & 3,0 \\
\hline & Média & 2,9 & 1,3 & 2,3 & $\mathrm{CV}=48,9 \%$ \\
\hline \multirow{3}{*}{29} & 'OR Mirante’ & 3,1 & 1,7 & 2,7 & $2,5 \mathrm{~A}$ \\
\hline & 'CD 104' & 4,5 & 2,3 & 5,2 & $4,0 \mathrm{~B}$ \\
\hline & Média & $3,8 \mathrm{~b}$ & $2,0 \mathrm{a}$ & $4,0 \mathrm{~b}$ & $\mathrm{CV}=42,0 \%$ \\
\hline \multirow{3}{*}{31} & ‘OR Mirante’ & 3,3 & 2,4 & 3,9 & $3,2 \mathrm{~A}$ \\
\hline & 'CD 104' & 6,0 & 2,0 & 5,2 & 4,4 B \\
\hline & Média & $4,6 \mathrm{~b}$ & $2,2 \mathrm{a}$ & $4,5 \mathrm{~b}$ & $\mathrm{CV}=42,8 \%$ \\
\hline \multirow{3}{*}{35} & 'OR Mirante’ & 3,3 & 2,5 & 4,2 & 3,3 A \\
\hline & 'CD 104’ & 6,4 & 2,1 & 6,5 & $5,0 \mathrm{~B}$ \\
\hline & Média & $4,9 \mathrm{~b}$ & $2,3 \mathrm{a}$ & $5,3 \mathrm{~b}$ & $\mathrm{CV}=46,7 \%$ \\
\hline \multirow{3}{*}{38} & 'OR Mirante’ & 4,1 & 2,1 & 3,3 & $3,1 \mathrm{~A}$ \\
\hline & 'CD 104’ & 5,9 & 1,6 & 5,9 & 4,5 B \\
\hline & Médias & $5,0 \mathrm{~b}$ & $1,8 \mathrm{a}$ & $4,6 \mathrm{~b}$ & $\mathrm{CV}=44,75 \%$ \\
\hline
\end{tabular}

Médias seguidas de mesma letra, minúscula na linha e maiúscula na coluna, não diferem entre si (Tukey, 5\%). 
Nas demais avaliações, não houve interação significativa ente os fatores, sendo a cultivar 'OR Mirante' sempre superior à 'CD 104', com menor severidade. A média do número de lesões de 'CD 104' ficou entre 32,62\% (aos 31DAS) e 76,80\% (aos 25DAS), superior ao número de lesões de 'OR Mirante'.

Em relação aos fungicidas utilizados, o difenoconzole foi mais eficiente que o carboxin + thiram, que se igualou à testemunha, com exceção da primeira avaliação, quando não foi possível notar diferença entre a testemunha e os fungicidas utilizados. Difenoconazole chegou a ter nível de controle superior à testemunha, chegando a reduzir em $150 \%$ a média do número de lesões em relação à testemunha, na última avaliação.

Apesar do carboxin + thiram ter sido eficiente no controle de Pyricularia grisea e Bipolaris sorokiniana em sementes de trigo da cultivar Anahuac nos estudos realizados por LASCA et al. (2001), no presente trabalho essa mesma eficiência não pôde ser notada para controle de $\boldsymbol{C}$. sativus inoculado em plântulas de trigo, uma vez que o produto se igualou à testemunha quanto ao número de lesões.

Por outro lado, avaliando a eficiência de fungicidas no tratamento de sementes para o controle da brusone nas folhas de arroz, TEIXEIRA et al. (1997) também não obtiveram diferença entre os fungicida carboxin + thiram, difenoconazole e a testemunha quanto à área foliar afetada, o que contrasta com os presentes resultados, uma vez que o difenoconazole foi superior à carboxin + thiram e à testemunha, quanto à eficiência de controle.

A eficiência do fungicida difenoconazole em relação à testemunha também foi observada no tratamento químico de sementes trigo, na cultivar 'OR-1' para controle de ferrugem da folha e oídio (GOULART, 1999), cuja proteção das plantas ocorreu até os 54 dias após a emergência, quando utilizou fungicida difenoconazole.

A ausência de diferença entre as sementes tratadas com carboxin + thiram e a testemunha pode ter sido ocasionada por um possível efeito residual curto do carboxin + thiram em relação ao difenoconazole, somada à alta pressão de inóculo induzida no experimento.

Na tabela 2, estão os dados de comprimento da parte aérea (CPA), da raiz (CR), massa fresca da parte aérea (MFPA), das raízes (MFR), massa seca da parte aérea (MSPA) e das raízes (MSR), pelos quais se constatou que não houve interação significativa ente os fatores em nenhuma das variáveis analisadas. O comprimento da parte aérea (CPA) foi maior para a cultivar 'CD 104' em relação à ‘OR Mirante’ e para a testemunha em relação à difenoconazole, não sendo possível observar diferença significativa entre carboxin + thiram com difenoconazole e carboxin + thiram com o tratamento testemunha.

Não foi possível observar diferença entre as cultivares em questão para as demais variáveis analisadas (comprimento, massa fresca e seca da parte aérea e das raízes). Em relação aos fungicidas, para estas variáveis, a testemunha foi estatisticamente superior, enquanto entre difenoconazole e carboxin + thiram não houve diferença significativa.

A partir de determinado nível de vigor da semente, praticamente não há resposta ao tratamento fungicida (CARVALHO \& NAKAGAWA, 2000). Com base nesta informação pode-se inferir que a cultivar 'OR Mirante' possivelmente tem maior vigor, uma vez que, para essa cultivar, os tratamentos fungicidas não diferiram da testemunha.

O fato de a testemunha ter sido superior aos tratamentos pode ser explicado por um possível efeito fitotóxico dos produtos no desenvolvimento das plantas. Nos estudos de BALARDIN \& LOCH (1987), o tratamento das sementes de centeio e aveia com thiram inibiu a germinação de sementes de aveia, além de interferir, negativamente, no comprimento de raiz e coleóptilo, indicando uma inibição do crescimento.

Pelos dados de área abaixo da curva de progresso da doença (AACPD) (Tabela 3), observouse interação significativa entre os fatores cultivar e fungicida; dentro da cultivar 'CD 104', difenoconazole demonstrou AACPD inferior à carboxin + thiram e à testemunha, que se igualaram, enquanto para ' $O R$ Mirante' não houve diferença entre os fungicidas. Dentro do fungicida difenoconazole não houve diferença entre as cultivares utilizadas, enquanto para carboxin + thiram e a testemunha houve maior AACPD para a cultivar 'CD 104'.

A partir desses resultados e com auxílio da figura 1 pode-se observar a maior eficiência de difenoconazole para as duas cultivares $\left(\mathrm{T}_{2}\right.$ e $\left.\mathrm{T}_{5}\right)$, com menor AACPD. Esse fungicida foi capaz de manter os menores níveis de doença, tanto para a cultivar 'OR Mirante’ quanto para 'CD 104'. Os resultados obtidos se assemelham ao dos estudos de TEIXEIRA et al. (1997), quando trabalharam com brusone do arroz e concluíram que não houve diferença entre AACPD de carboxin + thiram com a testemunha, mas discordam quando não encontram diferença de AACPD de difenoconazole em relação à carboxin + thiram e à testemunha.

Dessa forma, pode-se ainda inferir que há uma tendência à persistência prolongada de difenoconazole, uma vez que houve curvas com menor 
Tabela 2 - Análise de variância para as médias de comprimento da parte aérea (CPA) e da raiz em centímetros (CR), peso verde da parte aérea (PVPA) e das raízes em gramas (PVR), peso seco da parte aérea (PSPA) e das raízes em gramas (PSR), em duas cultivares de trigo submetidas ao tratamento de sementes com dois fungicidas e inoculados com $\boldsymbol{C}$. sativus nos primeiros estádios de desenvolvimento.

\begin{tabular}{|c|c|c|c|c|c|}
\hline & \multirow{2}{*}{ Cultivares } & \multicolumn{3}{|c|}{------------Fungicidas---------------------------------------- } & \multirow{2}{*}{ Médias } \\
\hline & & Carboxin + Thiram & Difenoconazole & Testemunha & \\
\hline \multirow{3}{*}{ СРA } & 'OR Mirante' & 28,3 & 27,1 & 29,7 & $28,3 \mathrm{~A}$ \\
\hline & 'CD 104' & 30,3 & 28,8 & 31,4 & $30,1 \mathrm{~B}$ \\
\hline & Média & $29,3 \mathrm{ab}$ & 27,9 a & $30,55 \mathrm{~b}$ & $\mathrm{CV}=8,8 \%$ \\
\hline \multirow{3}{*}{ CR } & 'OR Mirante’ & 18,8 & 19,3 & 20,3 & $19,4 \mathrm{~A}$ \\
\hline & 'CD 104' & 19,0 & 18,2 & 22,3 & $19,8 \mathrm{~A}$ \\
\hline & Média & 18,9 a & $18,7 \mathrm{a}$ & $21,3 \mathrm{~b}$ & $\mathrm{CV}=12,85 \%$ \\
\hline \multirow{3}{*}{ PVPA $\left(10^{-1}\right)$} & 'OR Mirante’ & 4,4 & 4,0 & 6,0 & $4,8 \mathrm{~A}$ \\
\hline & 'CD 104’ & 5,1 & 4,2 & 6,0 & $5,1 \mathrm{~A}$ \\
\hline & Média & 4,8 a & $4,1 \mathrm{a}$ & $6,0 \mathrm{~b}$ & $C V=23,6 \%$ \\
\hline \multirow{3}{*}{$\operatorname{PVR}\left(10^{-1}\right)$} & 'OR Mirante’ & 1,7 & 1,8 & 2,1 & $1,9 \mathrm{~A}$ \\
\hline & 'CD 104’ & 1,6 & 1,7 & 2,4 & $1,9 \mathrm{~A}$ \\
\hline & Média & $1,7 \mathrm{a}$ & $1,75 \mathrm{a}$ & $2,2 \mathrm{~b}$ & $\mathrm{CV}=22,3 \%$ \\
\hline \multirow{3}{*}{$\operatorname{PSPA}\left(10^{-2}\right)$} & 'OR Mirante’ & 5,7 & 5,5 & 7,5 & $6,2 \mathrm{~A}$ \\
\hline & 'CD 104' & 6,1 & 5,3 & 7,4 & $6,25 \mathrm{~A}$ \\
\hline & Média & 5,6 a & $5,4 \mathrm{a}$ & $7,4 \mathrm{~b}$ & $C V=20,2 \%$ \\
\hline \multirow{3}{*}{$\operatorname{PSR}\left(10^{-2}\right)$} & 'OR Mirante’ & 2,1 & 2,2 & 2,4 & $2,2 \mathrm{~A}$ \\
\hline & 'CD 104' & 2,1 & 2,0 & 2,7 & $2,3 \mathrm{~A}$ \\
\hline & Médias & 2,1 a & $2,1 \mathrm{a}$ & $2,5 b$ & $C V=20,65 \%$ \\
\hline
\end{tabular}

Médias seguidas de mesma letra, minúscula na linha e maiúscula na coluna, não diferem entre si (Tukey, 5\%).

inclinação do que carboxin + thiram e testemunha durante o período de avaliação. GOULART (1999) observou a eficiência de difenoconazole na proteção das plantas de trigo contra oídio até os 54 dias após a emergência. PICININI \& FERNANDES (2001), em experimento com a cultivar de trigo BR 43, observaram proteção contra ferrugem da folha por até 104 dias após a semeadura.

\section{CONCLUSÃO}

O fungicida difenoconazole aplicado via sementes é eficiente no controle de $\boldsymbol{C}$. sativus inoculado na parte aérea de plantas de trigo. No entanto, os dois fungicidas utilizados neste estudo interferem negativamente no crescimento das plantas.

Tabela 3 - Análise de variância da AACPD (área abaixo da curva de progresso da doença) para duas cultivares submetidas ao tratamento com dois fungicidas e inoculadas com $\boldsymbol{C}$. sativus.

\begin{tabular}{|c|c|c|c|c|}
\hline \multirow{3}{*}{ Cultivares } & \multicolumn{4}{|c|}{ 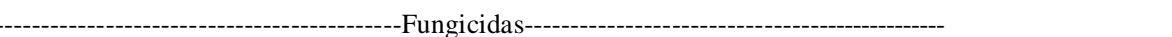 } \\
\hline & & & & Médias \\
\hline & Carboxin + Thiram & Difenoconazole & Testemunha & \\
\hline 'OR Mirante’ & 205,6 Аa & $134,3 \mathrm{Aa}$ & 214,4 Aa & 184,8 \\
\hline ‘CD 104’ & $351,4 \mathrm{Bb}$ & 125,3 Аа & $355,1 \mathrm{Bb}$ & 277,6 \\
\hline Médias & 278,5 & 129,8 & 285,25 & $\mathrm{CV}=34,6 \%$ \\
\hline
\end{tabular}

Médias seguidas de mesma letra, minúscula na linha e maiúscula na coluna, não diferem entre si (Tukey, 5\%). 


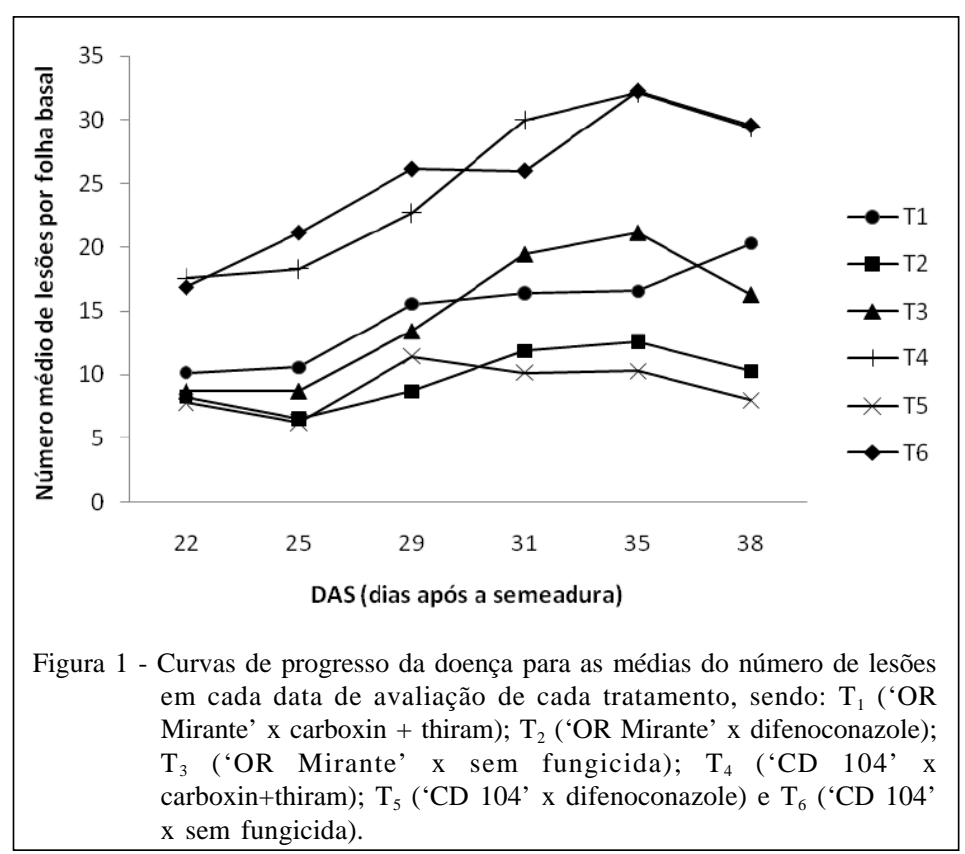

\section{REFERÊNCIAS}

ARRUDA, M.A. et al. Reação do trigo à Magnaporthe grisea nos diferentes estádios de desenvolvimento. Fitopatologia Brasileira, v.30, n.2, p.121-126, 2005. Disponível em: <http://www.scielo.br/ scielo.php?script=sci_arttext\&pid=S010041582005000200003 \&lng=pt\&nrm=iso\&tlng=PT $>$. Acesso em: 24 abr. 2010. doi: 10.1590/S0100-41582005000200003.

AZEVEDO, L.A.S. Tratamento de sementes com fungicidas visando o controle de patógenos na parte aérea. In: SIMPÓSIO BRASILEIRO DE PATOLOGIA DE SEMENTES, 4., 1996, Gramado, RS. Tratamento químico de sementes: Anais... Campinas: Fundação Cargill, 1996. p.83-91.

BALARDIN, R.S.; LOCH, L.C. Efeito de thiram sobre a germinação de sementes de centeio e aveia. Revista Brasileira de Sementes, v.9, n.1, p.113-117, 1987. Disponível em: $<$ http://www.agrolink.com.br/downloads/88340.pdf >. Acesso em: 30 abr. 2010.

BRASIL. Ministério da Agricultura, Pecuária e Abastecimento. Manual de análise sanitária de sementes. Brasília: Ministério da Agricultura e Reforma Agrária, 2009. 200p. (Anexo de: Regras para análise de sementes. Cap. 9: teste de sanidade de sementes).

CARVALHO, N.M.; NAKAGAWA, J. Sementes: ciência, tecnologia e produção. 4.ed. Jaboticabal: FUNEP, 2000. 588p.

EMBRAPA TRIGO. Cultura do trigo. Disponível em: <http:/ /www.cnpt.embrapa.br/culturas/trigo/index.htm>. Acesso em: 17 maio, 2010.

FRONZA, V. et al. Informações técnicas para a safra 2008: trigo e triticale. Londrina: Embrapa Soja, 2008. 147p. (Documentos 301).

GOULART, A.C.P.; PAIVA, F.A. Avaliação de fungicidas no controle das ferrugens do trigo. Pesquisa Agropecuária
Brasileira, v.26, n.11/12, p.1975-1981, 1991. Disponível em: <http://webnotes.sct.embrapa.br/pab/pab.nsf/FrAnual>. Acesso em: 21 abr. 2010.

GOULART, A.C.P. Controle do oídio e da ferrugem da folha pelo tratamento de sementes de trigo com fungicidas. Dourados: Embrapa Agropecuária Oeste, 1999. 26p. (Boletim de Pesquisa, 1). Disponível em: <http:// www.cpao.embrapa.br/publicacoes/online/zip/BP199901.pdf>. Acesso em: 30 abr. 2010.

JOSHI, L.M. et al. Mutiplication of inoculum of Helminthosporium turcicum on sorghum seeds. Indian Phytopatoly, v.22, n.3, p.146-148, 1969.

LASCA, C.C. et al. Controle de Pyricularia grisea e Bipolaris sorokiniana em sementes de trigo mediante tratamento com fungicidas. Arquivos do Instituto Biológico, v.68, n.1, p.5563, 2001. Disponível em: <http://www.biologico.sp.gov.br/docs/ arq/V68_1/11.pdf>. Acesso em: 19 mar. 2011.

MEHTA, Y.R. Manejo integrado de enfermedades del trigo. Santa Cruz de la Sierra: Imprenta Landivar, 1993. 314p.

PICININI, E.C.; FERNANDES, J.M. Controle da ferrugem da folha e da mancha bronzeada da folha de trigo pelo uso de fungicidas em tratamento de sementes. Fitopatologia Brasileira, v.26, n.1, p.100-100, 2001. Disponível em <http:/ /www.scielo.br/scielo.php?script=sci_arttext\&pid=S0100$41582001000100020 \& \operatorname{lng}=p t \& n r m=i s o \& t \operatorname{lng}=p t>$. Acesso em: 30 abr. 2010. doi: 10.1590/S0100-41582001000100020.

TEIXEIRA, E.A. et al. Eficiência relativa dos fungicidas sistêmicos, no tratamento de sementes para o controle da brusone das folhas de arroz. Revista Brasileira de Sementes, v.19, n.2, p.179184, 1997. Disponível em: http://www.abrates.org.br/revista/artigos/ 1997/v19n2/artigo07.pdf. Acesso em: 20 mar. 2011. 